\title{
Design and Performance Assessment of Continuous Crystallization Processes Resolving Racemic Conglomerates
}

DOI:

10.1021/acs.cgd.7b01618

\section{Document Version}

Accepted author manuscript

Link to publication record in Manchester Research Explorer

Citation for published version (APA):

Köllges, T., \& Vetter, T. (2018). Design and Performance Assessment of Continuous Crystallization Processes Resolving Racemic Conglomerates. Crystal Growth and Design. https://doi.org/10.1021/acs.cgd.7b01618

\section{Published in:}

Crystal Growth and Design

\section{Citing this paper}

Please note that where the full-text provided on Manchester Research Explorer is the Author Accepted Manuscript or Proof version this may differ from the final Published version. If citing, it is advised that you check and use the publisher's definitive version.

\section{General rights}

Copyright and moral rights for the publications made accessible in the Research Explorer are retained by the authors and/or other copyright owners and it is a condition of accessing publications that users recognise and abide by the legal requirements associated with these rights.

\section{Takedown policy}

If you believe that this document breaches copyright please refer to the University of Manchester's Takedown Procedures [http://man.ac.uk/04Y6Bo] or contact uml.scholarlycommunications@manchester.ac.uk providing relevant details, so we can investigate your claim.

\section{OPEN ACCESS}


This document is confidential and is proprietary to the American Chemical Society and its authors. Do not copy or disclose without written permission. If you have received this item in error, notify the sender and delete all copies.

\section{Design and Performance Assessment of Continuous Crystallization Processes Resolving Racemic Conglomerates}

\begin{tabular}{|r|l|}
\hline Journal: & Crystal Growth \& Design \\
\hline Manuscript ID & cg-2017-01618z.R1 \\
\hline Manuscript Type: & Article \\
\hline Date Submitted by the Author: & $19-J a n-2018$ \\
\hline Complete List of Authors: & $\begin{array}{l}\text { Köllges, Till; The University of Manchester, School of Chemical Engineering } \\
\text { and Analytical Science } \\
\text { Vetter, Thomas; University of Manchester, School of Chemical Engineering } \\
\text { and Analytical Science }\end{array}$ \\
\hline \multicolumn{2}{|l}{} \\
\hline
\end{tabular}

\section{SCHOLARONE}

Manuscripts 


\title{
Design and Performance Assessment of
} Continuous Crystallization Processes Resolving Racemic Conglomerates

\author{
Till Köllges and Thomas Vetter* \\ School of Chemical Engineering and Analytical Science, The University of Manchester, \\ Manchester, UK \\ E-mail: thomas.vetter@manchester.ac.uk \\ Phone: +441613064370
}

\begin{abstract}
Continuous crystallization processes achieving the complete resolution of racemic feed mixtures of conglomerate forming substances are presented. The processes considered rely on the principles of preferential crystallization or attrition-enhanced deracemization (Viedma ripening). A single mechanistic population balance model is shown to describe both operating modes. For the case of isothermal Viedma ripening, a shortcut method is introduced that allows the rapid and computationally efficient design of processes using a single or multiple ripening stages. The achievable productivity and enantiomeric purity are determined for all process variants in a wide range of operating conditions and Pareto optimal operating points are identified. Since our results are obtained with a consistent set of kinetics for all operating modes, an unbiased comparison is enabled. It is shown that the productivity of the ripening process can be improved by using cascades of multiple crystallizers, but that the preferential crystallization process still achieves higher productivity at full enantiomeric purity.
\end{abstract}




\section{Introduction}

Different enantiomers of the same substance can exhibit different effects on biological systems $^{1}$. Since most newly approved drugs are chiral ${ }^{2}$, manufacturing processes delivering chirally pure substances are important ${ }^{3}$. Several pathways towards enantiomerically pure products exist, either by avoiding the formation of unwanted enantiomers, e.g., through asymmetric synthesis or by using starting materials with the desired chirality, or by a separation process. A variety of such enantiomer separation processes are used industrially and have been well reported in the literature ${ }^{4}$; among them are chromatography ${ }^{5,6}$, membrane processes $^{7}$, and liquid-liquid extraction ${ }^{8}$. However, the mentioned processes typically deliver the product in diluted form in the liquid phase, so that they are often followed by a crystallization process that delivers the ultimately desired solid product. When instead designing a crystallization process to directly deliver enantiomerically pure solids from an enantiomerically impure starting point, the key aspects to consider are the underlying phase diagram, the ability of the enantiomers to form diastereomeric salts or co-crystals using chiral auxiliaries, as well as the composition of the feed mixture ${ }^{9,10}$. In this work, we consider crystallization processes that resolve conglomerate forming systems of enantiomers from a racemic feed mixture. Contrary to racemic compound forming systems, there is no thermodynamically stable form containing both enantiomers in the crystal lattice in conglomerate systems. However, macroscopic mixtures of crystals of the two enantiomers can form in a process.

For conglomerates two major crystallization process variants have been widely reported in the literature: preferential crystallization $(\mathrm{PC})$ and Viedma ripening (VR). In $\mathrm{PC}^{9,11}$ enantiopure seeds are preferentially grown to larger size from a supersaturated solution, while the counter enantiomer (distomer) remains in solution. Carried out in a batch, such a process must be stopped before the distomer nucleates to guarantee product purity. Viedma ripening $^{12}$ in contrast proceeds close to equilibrium and achieves complete resolution of an initially (nearly) racemic solid mixture by a complex interplay of crystal breakage/grinding, 

the racemization reaction in the liquid phase is a prerequisite for VR to work, it is noteworthy that including a racemization reaction in a preferential crystallization process enables complete resolution and $100 \%$ yield (if appropriate recycling operations are included in the overall process); without a racemization reaction the distomer is invariably a waste product.

In recent years, a potpourri of improved process variants involving either preferential crystallization, Viedma ripening, or combinations thereof have been reported in the literature, both operated in batch, as well as continuously. Studies on preferential crystallization were mainly focussed on introducing novel processing schemes to improve process stability, e.g. by avoiding nucleation of the counter enantiomer ${ }^{15-17}$, enabled continuous operation, e.g., coupled mixed suspension mixed product removal crystallizer (C-MSMPRC) configurations to lower the counter enantiomer supersaturation ${ }^{18-20}$, or on evaluating/improving process performance, e.g., by continuous seeding, adding an attrition unit, or a fines dissolution unit. $^{21-24}$ The focal points of studies on Viedma ripening were often placed on mechanistic aspects ${ }^{12,14,25}$, on widening the scope of its application (new classes of compounds ${ }^{26}$, metastable solid phases ${ }^{27}$, etc.), as well as exploring different operating modes (involving grinding $^{28-30}$, sonication ${ }^{31}$, temperature cycling ${ }^{32,33}$ or combinations thereof).

While demonstrating the feasibility as well as improving the robustness of a given process are important first steps, key performance indicators (KPIs), such as the attainable purity, the productivity, the process complexity, and the amount of waste generated per product formed need to be considered when deciding which process is used in manufacturing. In that respect, it is noteworthy that only a few of the recent studies targeting the resolution of enantiomers by crystallization have reported the productivity of the chosen process (a few examples are available for preferential crystallization in coupled systems ${ }^{16,17}$ and in fluidized bed crystallizers $(\mathrm{FBC})^{24}$ ), and equally few have attempted to rigorously optimize a given process including analyzing tradeoffs between $\mathrm{KPIs}^{10,34}$. The KPIs mentioned above are often in competition with each other and are dictated by the kinetics and thermodynam- 
ics of the substances involved, the process configuration, the operating parameters (batch time/residence time, feed concentration/initial concentration, etc.) and possible operational constraints (such as minimum and maximum temperatures, as well as maximum allowable suspension density in the crystallizer) ${ }^{10,34,35}$.

To showcase how widely the productivity of the processes reported in the recent literature varies, an overview is provided in Table 1. A direct comparison between these processes is not possible, since the studies often do not feature the same substance system (and are therefore subject to different kinetics). Furthermore, the reported processes were rarely rigorously optimized with a set of KPIs in mind. Our recent model-based study ${ }^{36}$ is no exception in that respect, because we placed our emphasis on feasibility and analyzed the possible steady states, rather than optimizing the KPIs and evaluating tradeoffs between them.

The goal of the present article is to analyze the tradeoff between two KPIs, productivity and enantiomeric purity, for continuous PC and VR processes, both involving racemization reactions. We thus aim to identify Pareto optimal operating points for all process configurations considered in this article. An operating point for a given process configuration is considered to be Pareto optimal when none of the KPIs can be enhanced without sacrificing performance in another. In the context of this article, this means that we establish operating points where productivity cannot be increased without sacrificing enantiomeric purity (and vice versa).

The remainder of this article is structured as follows: first, we present the process configurations considered. Second, we introduce a detailed population balance equation model that is able to describe all process configurations consistently. Third, to avoid the computational expense that is associated with the detailed population balance model (when it would be used for the optimization and evaluation of multiple process configurations), we propose and validate a novel shortcut method for isothermal VR processes. Using both methods, Paretooptimal results for all process configurations are then reported in the results section. Lastly, differences in performance among the process configurations are highlighted and conclusions 


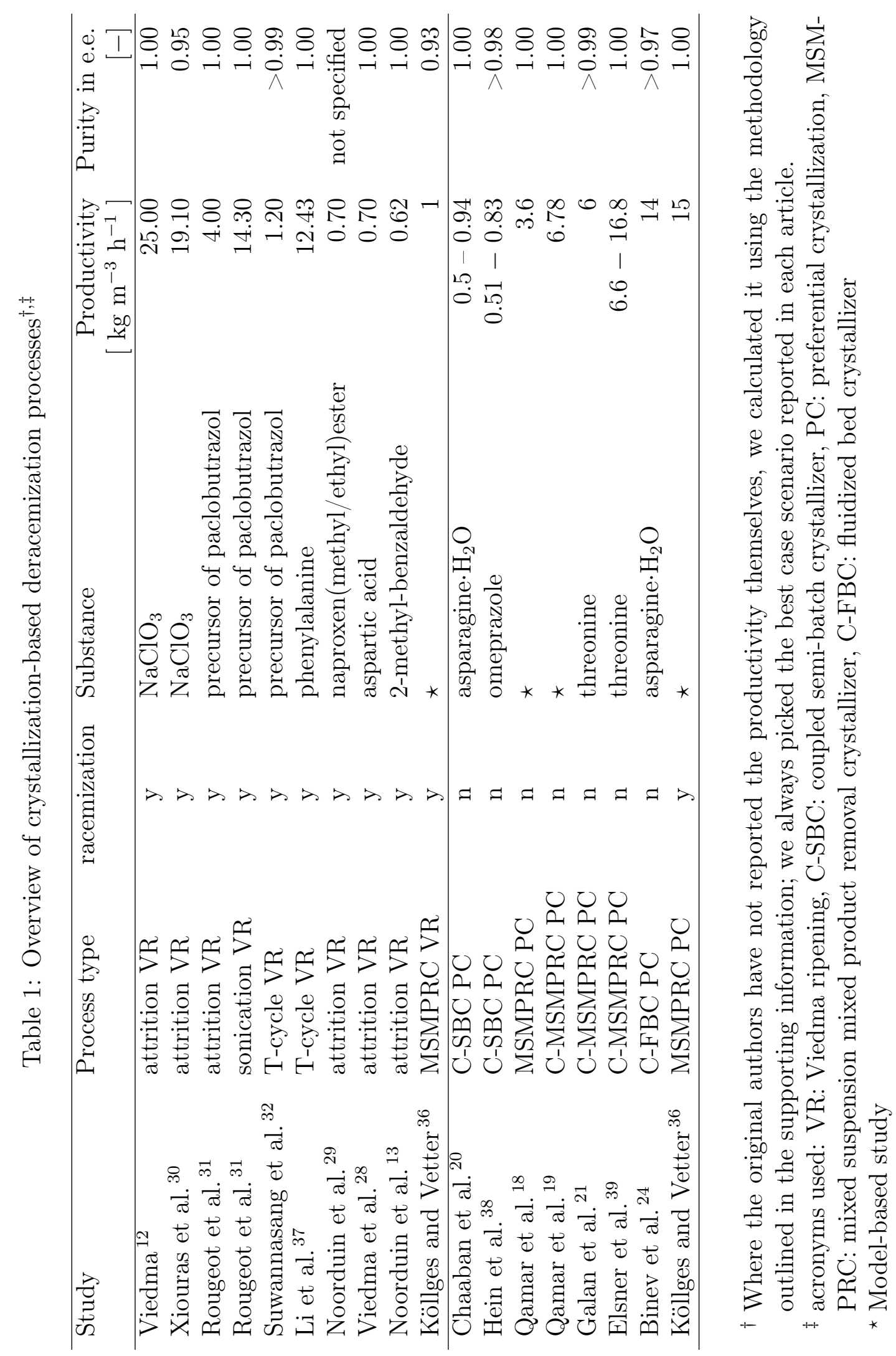


about the suitability of each process configuration are presented.

\section{Process variants and performance metrics}

Two main process types accomplishing the separation of racemic conglomerates are considered here: a continuous preferential crystallization process (Figure $1(\mathrm{~A})$ ) and a continuous Viedma ripening process (Figure $1(\mathrm{~B})$ ). We have designed both processes to start from a racemic feed solution and to be fully integrated, so that under ideal operation no waste is generated, all product is recovered and all distomer molecules are converted to the desired enantiomer. The latter requires a liquid phase racemization reaction, which is optional in regular PC, but required for VR, and appropriate mother liquor recycling as shown in Figure 1. Central to both processes are mixed suspension mixed product removal crystallizers (MSMPRCs), which are connected to milling units that provide attrition.

In flowsheet $(\mathrm{A})$ the MSMPRC is fed with a supersaturated solution of racemic composition that stems from preceding chemical synthesis steps. By providing seed crystals with an enriched composition during the start up phase and selecting appropriate feed concentration and residence time, a steady state with pure solid phase composition can be obtained from the MSMPRC $19,21,23,24,36$. Suspension is continuously transferred into the filtration unit, where the solids are separated from the solution. The mother liquor from the filtration unit (which contains remaining product molecules, the racemization catalyst and solvent) is recycled back to the crystallizer. Since solvent is continuously introduced in the feed, a complete recycle of the mother liquor would lead to a volume increase in the MSMPRC. It is thus vital to remove part of the solvent before recycling the mother liquor into the crystallizer. This has been drawn as a generic "solute concentrator" unit, which could be a distillation unit or a membrane process preferentially removing solvent. ${ }^{40}$

In Figure 1 (B) we introduce a flowsheet where a pre-crystallization step is followed by one ore more ripening stages that successively increase the enantiomeric excess. The pre- 
crystallization stage is run in such a way as to obtain maximum productivity regardless of enantiomeric purity, i.e., it generates a racemic mixture of crystals. After the filtration unit, the mother liquor is treated using a solute concentrator, as described for flowsheet (A), and recycled into the pre-crystallizer. Running the pre-crystallization step in this way allows choosing the suspension density for the following ripening stages (up to a maximum operatable/stirrable level). As is typical for VR, the ripening stages operate close to equilibrium in terms of liquid phase concentration, but with successively increasing enantiomeric excess in the solid phase. After the ripening stage(s), a second filtration unit is included in the flowsheet, where the final solid product is obtained and the mother liquor is recycled back to the first ripening stage. In terms of productivity, it can be advantageous to bypass racemic solids directly from the pre-crystallization stage and blend them with the enriched product of the last ripening stage, i.e., essentially sacrificing purity for productivity.

When comparing both flowsheets, we realize that flowsheet $(B)$ requires an additional filtration unit. Operating only one filtration unit at the end of the process chain in flowsheet (B) would be possible, however, one would relinquish control over the suspension density in the ripening stages, because the suspension density is then determined in the pre-crystallization stage. We also note that, for a recycle to work, both process flowsheets require a solute concentrator to be in operation. Since one would have to remove similar amounts of solvent in both processing flowsheets (presuming that the feed originates from the same chemical synthesis steps), we expect that this unit would affect the productivity of flowsheet (A) and (B) similarly; its operation would therefore not be a deciding criterion to choose among the two processes.

Naturally, there are operational constraints on continuously operated units, and constraints of thermal stability of product molecules and catalyst, fouling, etc. ${ }^{23,36}$ that would need to be considered. Additionally, when working with more complex mixtures (i.e., more components than the two enantiomers and a solvent), purge streams might be necessary to prevent the buildup of impurities, however, we have not included them in Figure 1 for the 


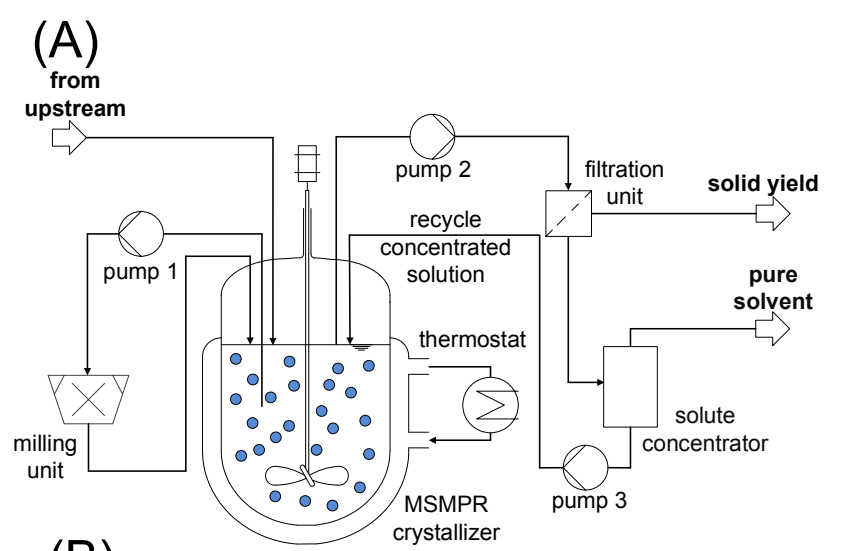

(B)

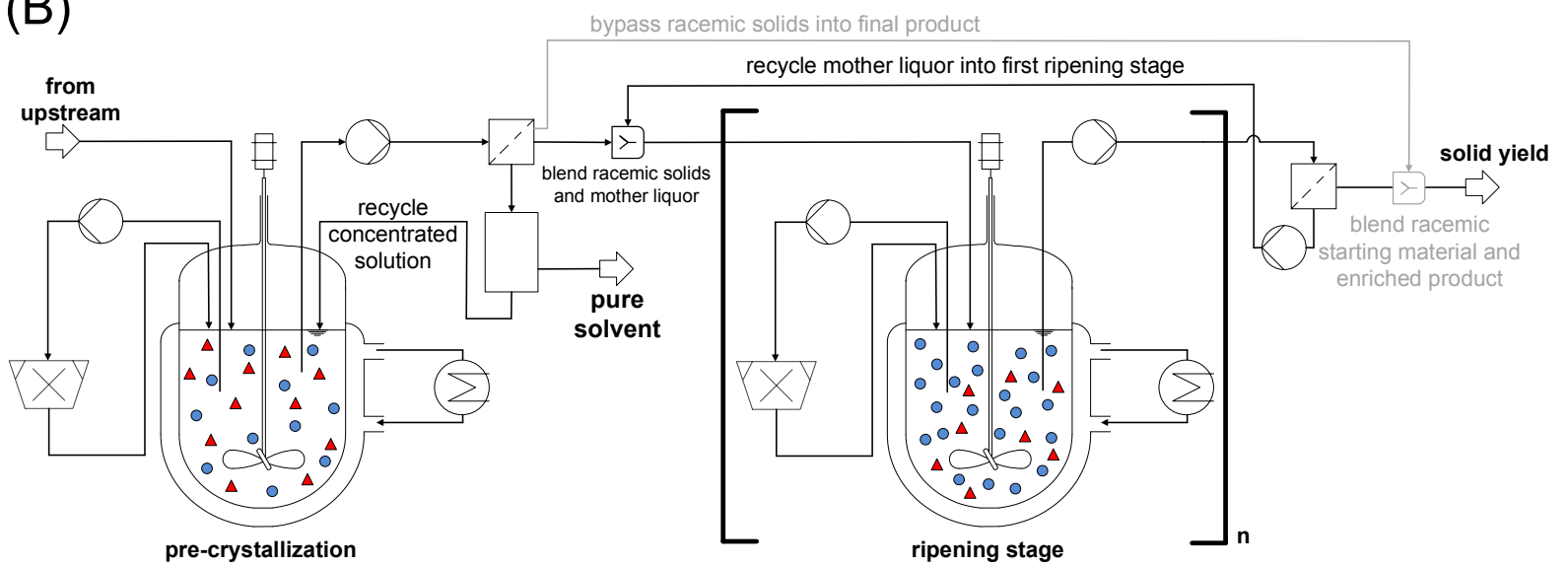

Figure 1: The two processes considered here: (A) Continuous preferential crystallization flowsheet with mother liquor recycle and solvent removal, (B) continuous Viedma ripening flowsheet with a variable number of ripening stages preceded by a pre-crystallization stage that yields a racemic mix of crystals. Drawn in grey is an optional variant, i.e., a partial bypass of racemic crystals from the pre-crystallization stage into the final solid product. 
sake of simplicity.

In the subsequent sections, we will generate Pareto-optimal process configurations with respect to enantiomeric purity and productivity for both process types. To reach this goal we optimize the suspension density and the residence times in the ripening stages of flowsheet (B) and the feed concentration and residence time of the MSMPRC in flowsheet (A).

We quantify the productivity, $P$, of the process variants, in terms of the mass of solids produced per time per volume of all crystallizers:

$$
P=\frac{\dot{m}_{\text {product }}}{V_{\text {process }}}\left[\frac{\mathrm{kg}}{\mathrm{m}^{3} \mathrm{~h}}\right]
$$

where the volumes of the ancillary units have been neglected, as they are roughly equal between the different process variants. For the continuous crystallization processes discussed above, this can be conveniently calculated using the suspension density in the last crystallizer and the sum of their residence times, i.e.:

$$
P=\frac{\rho_{\mathrm{sus}}}{\sum_{i=1}^{n} \tau_{i}}=\frac{\left(\mu_{3, \mathrm{~S}}+\mu_{3, \mathrm{R}}\right) k_{\mathrm{v}} \rho_{\mathrm{c}}}{\sum_{i=1}^{n} \tau_{i}}
$$

where $\rho_{\text {sus }}$ is the suspension density and $\tau_{i}$ the residence time in the $i$-th crystallizer. On the right hand side of Eq. (2), we have expressed the suspension density with quantities directly appearing in the population balance equation model presented below. $\mu_{3, j}$ is the third moment of the particle size distribution of enantiomer $j$ in the last crystallizer, $k_{\mathrm{v}}$ is the volumetric shape factor of the particles in the crystallizer and $\rho_{c}$ is the crystal density (here chosen to be $\pi / 6$ and $1568 \mathrm{~kg} \mathrm{~m}^{-3}$, respectively). The definition of the third moment of the particle size distribution is:

$$
\mu_{3, j}=\int_{0}^{\infty} L^{3} n_{j}(L) \mathrm{d} L \quad \text { with } \quad j \in\{\mathrm{R}, \mathrm{S}\}
$$


where $n_{j}$ is number density distribution of the crystals of enantiomer $j$ in the crystallizer and $L$ is the characteristic length of the particles. To quantify the enantiomeric purity of the solids, we use the enantiomeric excess, e.e.:

$$
\text { e.e. }=\frac{m_{\mathrm{S}}-m_{\mathrm{R}}}{m_{\mathrm{S}}+m_{\mathrm{R}}}=\frac{\mu_{3, \mathrm{~S}}-\mu_{3, \mathrm{R}}}{\mu_{3, \mathrm{~S}}+\mu_{3, \mathrm{R}}}
$$

Note that we defined the productivity in this work including both enantiomers, however, the production rate of only the desired enantiomer, say S, can be calculated from this by:

$$
P_{\mathrm{S}}=\frac{(e . e .+1)}{2} P
$$

Apart from enantiomeric purity and productivity, a complete process evaluation would also account for process complexity and maturity, operation cost (energy consumption, etc.), robustness, maintenance needs, as well as equipment costs. However, such an analysis is strongly process and product specific and lies outside the scope of this work.

\section{Process model}

In order to study the behavior of the above processes, population balance equations (PBEs) can be used. For each crystallizer in the flowsheets, two population balance equations, one for each enantiomer, are coupled with the respective mass balances for the liquid phase. The literature on Viedma ripening ${ }^{13,14,36}$ suggests that the PBEs must be able to describe Ostwald ripening (size-dependent growth and dissolution), crystal breakage, and agglomeration, and include racemization of the enantiomers in solution, in order to describe all experimental observations made on isothermal Viedma ripening experiments. A suitable model has first been described by Iggland and Mazzotti ${ }^{14}$, which is adapted here to the continuous flowsheets presented above (in accordance with our previous work ${ }^{36}$ ). We thus write for the solid phases in the crystallizer 


$$
\begin{aligned}
\frac{\partial n_{j}(L, t)}{\partial t} & =-\frac{\partial\left(G\left(S_{j}, L\right) n_{j}(L, t)\right)}{\partial L} \\
& +\frac{L^{2}}{2} \int_{0}^{L} \frac{A\left(\sqrt[3]{L^{3}-\lambda^{3}}, \lambda\right) n_{j}\left(\sqrt[3]{L^{3}-\lambda^{3}}, t\right) n_{j}(\lambda, t)}{\left(L^{3}-\lambda^{3}\right)^{2 / 3}} \mathrm{~d} \lambda \\
& -n_{j}(L, t) \int_{0}^{\infty} A(L, \lambda) n_{j}(\lambda, t) d \lambda \\
& +\int_{L}^{\infty} K(\lambda) d(\lambda, L) n_{j}(\lambda, t) \mathrm{d} \lambda-K(L) n_{j}(L, t) \\
& + \text { inflow }- \text { outflow with } \quad j \in\{\mathrm{R}, \mathrm{S}\}
\end{aligned}
$$

where $n_{j}(L, t)$ is the number density distribution of crystals of enantiomer $j$ in the crystallizer, $L$ is the characteristic length of the crystals, $G$ is the size-dependent growth rate (used to model Ostwald ripening), $A(\lambda, L)$ is the agglomeration kernel, $K(L)$ is the breakage rate and $d(\lambda, L)$ is the daughter distribution of particles formed upon breakage events. Writing the PBE in this way, we have treated the crystallizer and wet mill combination as a single processing unit. The daughter distribution and the breakage rate in the PBE could therefore in reality be tuned by altering the flow rate of suspension going through the mill and the mill's rotation speed. All constitutive model equations and the values of the kinetic parameters occurring in them are summarized in Table 2. The kinetic constants were selected to be in the right order of magnitude to yield realistic ripening times and growth rates, as discussed in ${ }^{36}$. They do not, however, represent a specific model substance. The material balances can be written as:

$\frac{\mathrm{d} c_{j}}{\mathrm{~d} t}=-3 k_{\mathrm{v}} \rho_{\mathrm{c}} \int_{0}^{\infty} L^{2} n_{j}(L, t) \mathrm{d} L+k_{\mathrm{r}}\left(c_{k}-c_{j}\right)+$ inflow - outflow with $j, k \in\{\mathrm{R}, \mathrm{S}\}$ and $j \neq k$

where $k_{\mathrm{r}}$ is the rate constant of the first order racemization reaction that occurs in the liquid phase. Eqs. (6) and (7) describe the dynamics of a single crystallizer (the indices to identify the $i$-th crystallizer were not included for the sake of simplicity). Therefore, for each crystallizer in the flowsheet two population balance equations and two material balances need 
Table 2: Constitutive model equations and kinetic rate constants.

mechanism constitutive model equation

\begin{tabular}{lll}
\hline agglomeration & $A(\lambda, \eta)=\left(\frac{\lambda+\eta}{2}\right)^{3} \frac{a_{2}}{1+a_{1} g(\lambda, \eta)}$ & $\begin{array}{l}a_{1}=10^{20} \mathrm{~m}^{-2} \\
a_{2}=10^{15} \mathrm{~s}^{-1}\end{array}$ \\
\hline breakage & $d(\lambda, \eta)=\frac{(\lambda \eta)^{2}}{\lambda^{2}+\eta^{2}-\lambda \eta}$ & \\
& $K(L)=k_{\mathrm{b}, 1} L^{k_{\mathrm{b}, 2}}$ & \\
\hline growth & $G\left(S_{j}, L\right)=k_{g}\left(S_{j}-\exp \left(\frac{\alpha}{L}\right)\right)$ & $\begin{array}{l}k_{\mathrm{b}, 1}=0.1 \mathrm{~s}^{-1} \\
k_{\mathrm{b}, 2}=1 \\
q=6\end{array}$ \\
\hline racemization & $r_{j}=k_{\mathrm{r}}\left(c_{\mathrm{k}}-c_{\mathrm{j}}\right) \quad$ with $j, k \in\{\mathrm{R}, \mathrm{S}\} ; j \neq k$ & $\begin{array}{l}k_{\mathrm{g}}=10^{-6} \mathrm{~m} \mathrm{~s}^{-1} \\
\alpha=3.0884 \times 10^{-9} \mathrm{~m}\end{array}$ \\
\hline
\end{tabular}

to be solved. Note that we have not spelt out the in- and outflow terms of the crystallizer in Eqs. (6) and (7) as they are changing from case to case in the above flowsheets.

Since our focus in this work is on the analysis of the crystallization process, we are using simple models to describe the ancillary processing units (filtration, solute concentrator). The separation of liquid and solid in the filtration unit is assumed to be $100 \%$, i.e., without loss of solution in the solid product. In the solvent removal unit we assume that $50 \%$ of the solvent in the incoming stream is selectively removed.

The PBEs above are discretized into size intervals using a central finite difference method. In order to guarantee the fulfillment of an overall mass balance to within $1 \%$ error, the number of size intervals, $N$, was chosen to be 200-600 per population (the higher number of intervals is required for flowsheet (B)). The resulting sets of ordinary differential equations were then solved using the built-in ode15s solver in MATLAB2016a on a Windows work station with an i7 $5820 \mathrm{~K}$ at $3.3 \mathrm{GHz}$ processor and $32 \mathrm{~GB}$ RAM. To solve a process of type (B) with one ripening stage until steady state conditions were reached required a computational time in the order of 10 hours - and longer in the case of multiple ripening stages. Clearly, the evaluation of many such cases in the context of an optimization quickly becomes computationally unreasonable. This has prompted us to develop a much faster shortcut method that allows the rapid evaluation of productivity and enantiomeric purity for flowsheets of 
type (B).

\section{Shortcut method}

\subsection{Methodology}

The full population balance equation model becomes computationally intensive for long residence times and for multiple crystallizers in series, not even accounting for the kinetic parameter estimation experiments. The completely model-free alternative, i.e., experimentally screening all process conditions using a full factorial design and including multiple process configurations, would be even worse from a time and material consumption standpoint. This motivated us to consider the development of a shortcut design method for process flowsheets of type (B). To arrive at such a method, we first recall that a solution to the PBE model (Eqs. (6) and (7)) yields knowledge of the full particle size distribution for both enantiomers at every instant of time. Such detailed information is not always needed to perform a productivity and purity analysis. It therefore makes sense to create a reduced model that only describes the quantities we are chiefly interested in. Expressing, for example, the evolution of the e.e. in a batch crystallizer, we could write

$$
\frac{\partial e . e .}{\partial t}=f\left(n_{j}(L, t), n_{k}(L, t), n_{0, j}(L, t), n_{0, k}(L), \text { all kinetics }\right) \text { with } j, k \in\{\mathrm{R}, \mathrm{S}\} \text { and } j \neq k
$$

where $n_{0, j}$ is the initial size distribution of particles of enantiomer $j$. In both Eq. (8) $f$ is a complex function depending on the kinetics of all mechanisms involved, on the PSDs of both enantiomers and also on the PSDs of the seeds. However, it is likely that some of the kinetic processes and influence factors contributing to $f$ will be dominating others in the sense that they are constituting the rate-limiting step.

To arrive at a possible simplification for $f$, we consider the evolution of the solid phase enantiomeric excess over time in an isothermal batch crystallizer. In Figure 2 (left) an 


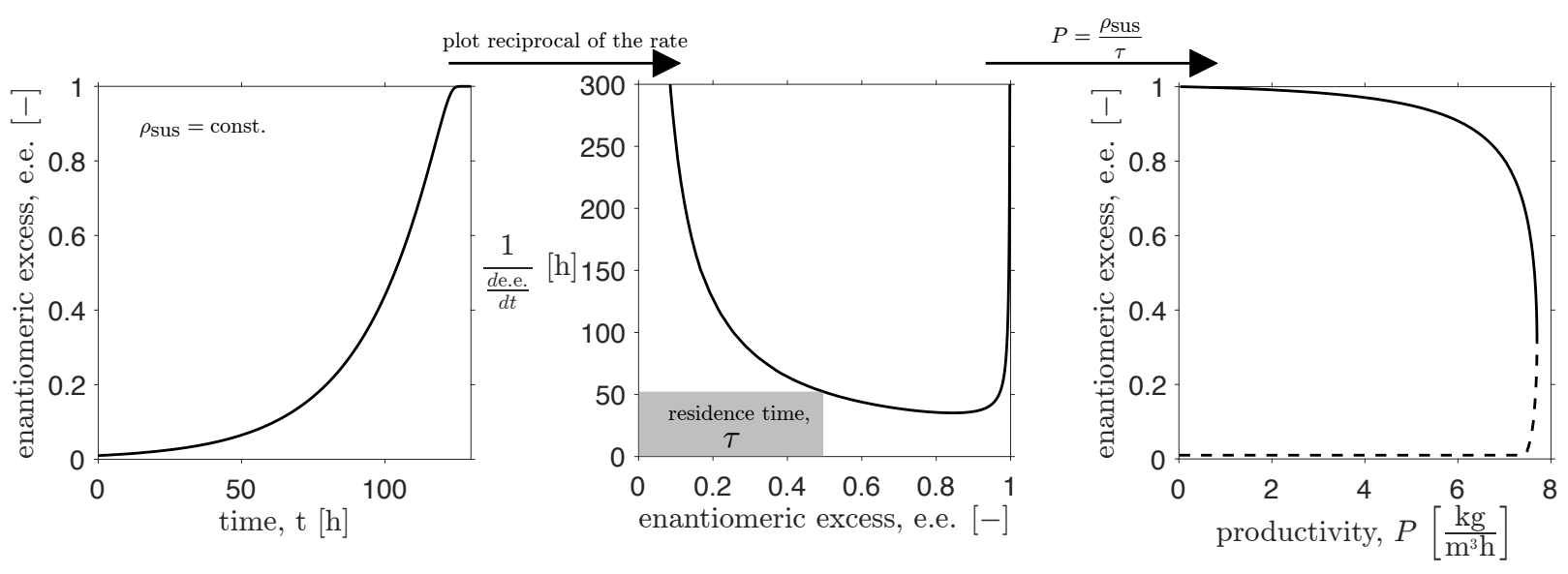

Figure 2: (left) The e.e. vs. $t$ curve of a batch process with a suspension density of $200 \mathrm{~kg}$ $\mathrm{m}^{-3}$. (middle) Levenspiel plot for Viedma ripening processes (inverse of the slope of the e.e. vs. $t$ curve against enantiomeric excess). The area drawn equals the residence time of a ripening stage yielding product with $e . e \cdot$ out $=0.5$. (right) The productivity vs. enantiomeric excess curve, calculated from the residence times and the suspension density. The solid line represents the Pareto set, while the points on the dashed line are suboptimal.

example of such a curve is shown, which was obtained using the full PBE model with the kinetics defined above, with suspension density $\rho_{\text {sus }}=200 \mathrm{~kg} \mathrm{~m}^{-3}$, initial enantiomeric excess e.e. ${ }_{0}=0.01$ and seed crystals following a normal distribution with mean of $40 \mu \mathrm{m}$ and standard deviation of $10 \mu \mathrm{m}$. The curve shows the typical autocatalytic behavior observed in batch Viedma ripening. In the following, we will treat such curves as the "fingerprint" of a Viedma ripening process and will approximate the dynamics of the process using the e.e. as the single deciding variable; we therefore simplify Eq. (8) to:

$$
\frac{\mathrm{de.e.}}{\mathrm{d} t} \approx \tilde{f}(\text { e.e. })
$$

Assuming this approximation is valid (which will be checked below), we draw an analogy between the e.e. in a deracemization process and the conversion in liquid phase reactions. Using this analogy, we can proceed to use a classical chemical reaction engineering (CRE) strategy to arrive at optimized process configurations. In CRE, Levenspiel plots, i.e., plots of conversion against the inverse of the reaction rate, can be used to find the residence time required in a reactor to arrive at a desired conversion (see Levenspiel ${ }^{41}$, Chapter 6, p. 140- 
144). In order to apply this concept to Viedma ripening processes, we generate a Levenspiel plot by drawing $1 / \tilde{f}$ against the e.e., as shown in Figure 2 (middle). The residence time of an MSMPRC converting an inlet stream with e.e.in to an outlet with e.e.out is then given by:

$$
\tau=\frac{e . e \cdot \text { out }-e . e \cdot \text { in }}{\tilde{f}(e \cdot e \cdot \text { out })}
$$

In the Levenspiel plot the residence time of an MSMPRC can thus be shown as a rectangle, as exemplified in Figure 2 (middle) for e.e.in $=0$ and e.e. out $=0.5$. Of course, similar rectangles could be drawn and the respective residence times calculated for a range of values of e.e.out. From the calculated residence times and knowledge of the suspension density, it is possible to calculate the corresponding productivities using Eq. (2) and these data can then be combined into a productivity vs. enantiomeric excess plot as shown in Figure 2 (right). This figure elucidates the tradeoff between enantiomeric excess and productivity. Since higher enantiomeric excess at the same productivity is always desirable, the lower branch (dashed line) of this curve is dominated by the upper branch (solid line) in a Pareto sense.

In applying this methodology, we have used a fingerprint curve from a batch Viedma ripening process to elucidate the existing tradeoff between enantiomeric excess and productivity in a single ripening stage in flowsheet (B) and we have simplified the description of the dynamics of the Viedma ripening process from a complex integro-differential equation (Eq. (6)) into a simple arithmetic calculation (Eq. (10)) and a look up table (i.e., data included in the fingerprint curve). These are strong simplifications and a few comments about the limitations and prerequisites of this approach are worth making and the results of this approach need to be validated. First, we point out that the e.e. vs. $t$ curve is dependent on the suspension density and temperature. Hence a batch e.e. vs. $t$ curve should only be used to generate Pareto sets for crystallizers operating at the same suspension density and temperature. Second, the seed particle size distribution should not have a major impact on 
the e.e. vs. $t$ curve. This means that the overall deracemization process must be slow in comparison to a process that impacts strongly on the PSD. In practice, it would be easiest to increase the attrition rate in a process to ensure this (e.g., by choosing an appropriate wet mill and its operating conditions).

\subsection{Validation}

The suitability of the shortcut method to deliver Pareto optimal enantiomeric excess vs. productivity data for the specific set of kinetics considered in this work will be evaluated now. To this end, the results of the shortcut method are compared to solutions of the full PBE model. In Figure 3 (left), we present data for a process of flowsheet (B) with one ripening stage operating at suspension densities of $200 \mathrm{~kg} \mathrm{~m}^{-3}$ (blue) or $400 \mathrm{~kg} \mathrm{~m}^{-3}$ (green). The circles represent steady state data obtained from the full PBE model (Eq. (6)), while the lines represent results from the shortcut method detailed above.
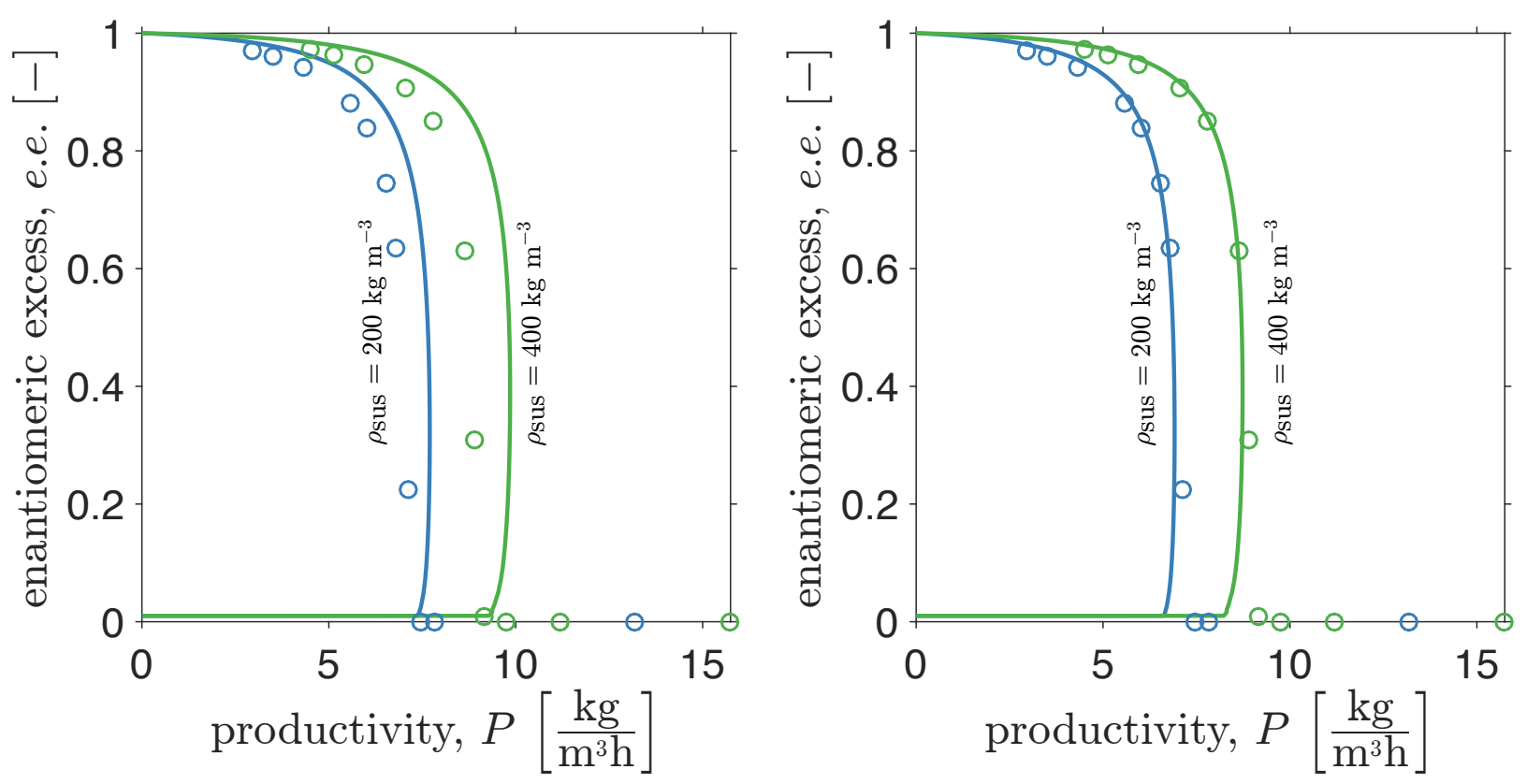

Figure 3: Enantiomeric excess vs. productivity data for $\rho_{\text {sus }}$ of $200 \mathrm{~kg} \mathrm{~m}^{-3}$ (blue) and 400 $\mathrm{kg} \mathrm{m}^{-3}$ (green) for a single ripening stage. (left) The data obtained using the shortcut method is shown as solid lines, while the circles represent data obtained from the full PBE model. (right) The productivity obtained from the shortcut method has been modified using Eq. (11). 
The shape of the curve obtained from the shortcut method is in good agreement with the results obtained from the full PBE model, except for data points which have an enantiomeric excess near zero. For the full PBE model low productivity and zero purity results stem from low residence time simulations, where the feed material is pushed through the crystallizer without Viedma ripening taking place. Conversely, the data points of the shortcut method at low purity stem from the early section in the e.e. vs. $t$ curve where the seed crystals still influence the curve substantially. These facts combined make the misfit between shortcut method and full PBE model at low e.e. unsurprising. This misfit is of little practical consequence. At high enantiomeric purity the shortcut method describes the results of the full PBE model well when they are scaled with a constant factor, i.e.:

$$
P_{\text {scaled }}(\text { e.e. })=\omega P_{\text {shortcut }}(\text { e.e. })
$$

which is shown in Figure 3 (right). In Eq. (11), $\omega$ is weakly dependent on suspension density ( $\omega=0.898$ for $\rho_{\text {sus }}=200 \mathrm{~kg} \mathrm{~m}^{-3}$ and $\omega=0.887$ for $\rho_{\text {sus }}=400 \mathrm{~kg} \mathrm{~m}^{-3}$; calculated by comparing full PBE model and shortcut method data). Given the strong simplifications used when generating the shortcut method and its ease of use, the quality of the agreement at high enantiomeric purity is astounding and potentially impactful. Rather than having to estimate kinetic parameters for all mechanisms included in the full PBE model from a large experimental dataset, an accurately measured enantiomeric excess vs. time curve from a single batch Viedma ripening experiment and one additional continuous experiment (to determine $\omega$ ) is enough to predict the full enantiomeric excess vs. productivity curve. The use of the shortcut method for kinetics different from the ones used here requires further validation, but the good agreement between full PBE model and shortcut method achieved with the kinetics used here, justifies the use of the shortcut method to generate full Pareto sets for the process variants shown in flowsheet (B) (cf. Figure 1). 


\section{Results and discussion}

In this section the tradeoff between two KPIs, productivity and enantiomeric purity, will be analyzed for flowsheets (A) and (B) by reporting Pareto optimal solutions using the full PBE model for flowsheet $(\mathrm{A})$ and the shortcut method for flowsheet (B). We analyze this tradeoff first for cases with a single MSMPRC and pre-crystallization plus one ripening stage (flowsheet (B)) before also considering flowsheet (B) with multiple ripening stages. Finally, in the conclusion section, we will compare all process configurations.

\subsection{Processes with a single MSMPRC}

In our previous study ${ }^{36}$ we investigated whether enantiomer separation in single MSMPRC processes following flowsheets (A) and (B) is feasible. In Figure 4, we present the steady state data obtained from the full population balance equation model again, however now we also quantified the productivity (grey lines) and the suspension density (white lines). The color map indicates the enantiomeric purity reached at each given steady state. On the left data of flowsheet $(\mathrm{A})$ operated at residence times between 1 and 5 hours and inlet concentrations of 35 to $70 \mathrm{~g} \mathrm{~kg}^{-1}$ are presented and on the right data for a single ripening stage in flowsheet (B) with solid feed rates between 1 and $10 \mathrm{~kg} \mathrm{~h}^{-1}$ and residence times from 5 to $25 \mathrm{~h}$ are presented.

In Figure 4 (left), the dissolved racemic starting material is converted either fully to the desired enantiomer (red area, e.e.out $=1$ ), or not at all, when both enantiomers are found in racemic composition in the solid product (blue area, e.e. out $=0$ ). There is no loss of starting material, because the solute is fully recovered using the recycle including the solute concentrator, shown in flowsheet (A). This leads to horizontal suspension density contour lines. The suspension densities obtained in this process would be considered well below the operability limit of industrial crystallizers (often considered to be in the range of 200 to $400 \mathrm{~kg} \mathrm{~m}^{-3}$; depending on the rheology of the suspension). The transition between pure 

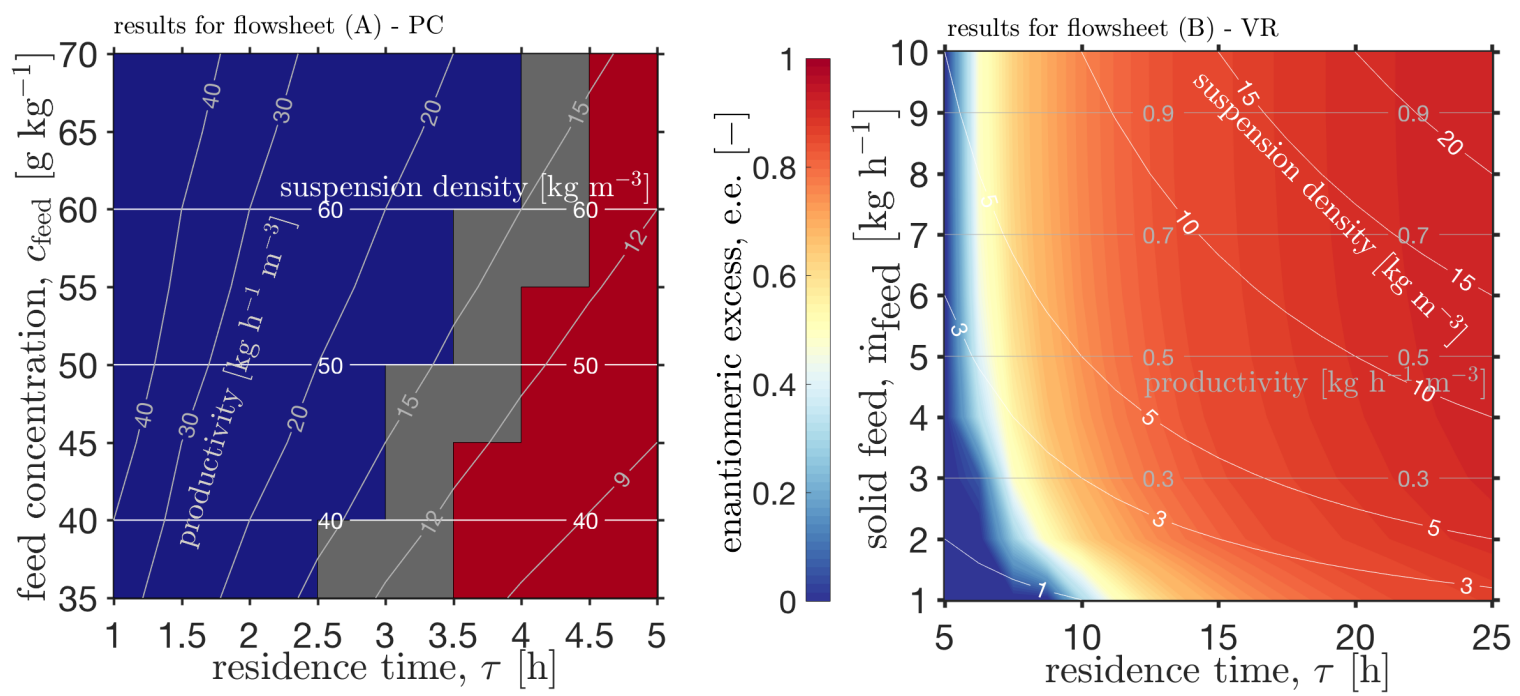

Figure 4: Analysis of purity, suspension density and productivity of single stage MSMPR crystallizers. The PC process (flowsheet $(\mathrm{A})$ ) is shown on the left; the continuous VR process (flowsheet $(\mathrm{B})$ ) is shown on the right. In both plots the background color represents the purity in solid e.e. (the scale is the same for both figures and shown on the colorbar in the middle), whereas the grey contour lines give the productivity in $\mathrm{kg} \mathrm{h}^{-1} \mathrm{~m}^{-3}$, and the white contour lines the suspension density in $\mathrm{kg} \mathrm{m}^{-3}$. In the grey area on the left no process simulations were performed and the enantiopurity is thus unknown. 
and racemic steady states lies somewhere in the grey area. As seen from the productivity contour lines crossing the grey section, this will mean that when analyzing the tradeoff between productivity and enantiomeric purity for the PC process, there will be some residual uncertainty with respect to the productivity achievable at enantiomeric purity, as indicated in Figure 5.

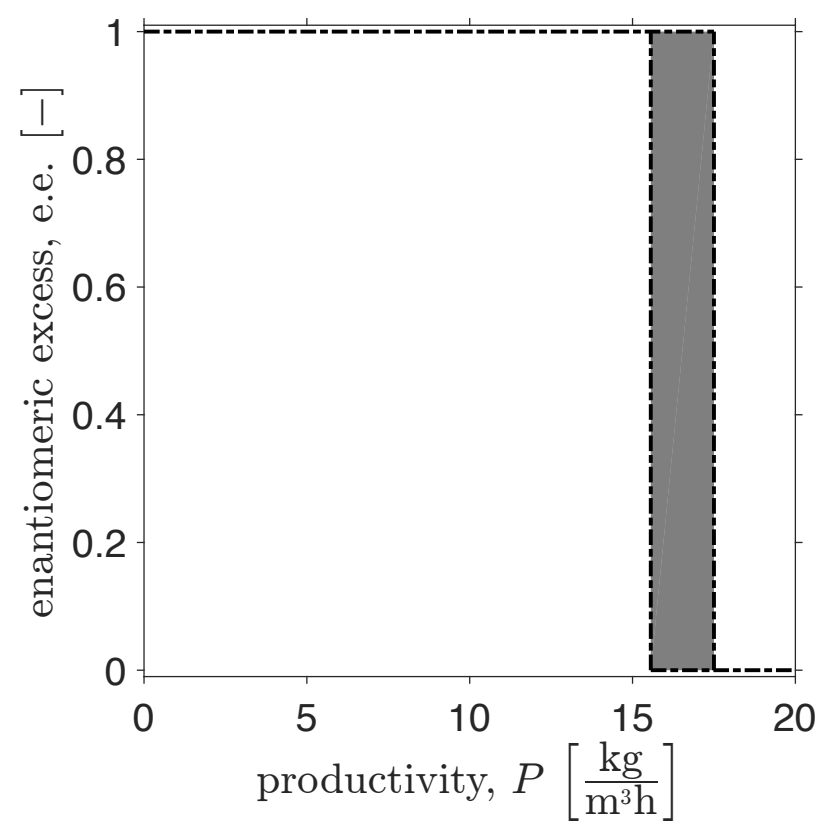

Figure 5: Pareto set with respect to productivity and enantiomeric excess for the PC process (flowsheet (A) based on data presented in Figure 4. The grey area reflects the presence of the uncertainty region in that figure: the actual Pareto set is located between the two steps.

In flowsheet (B), Figure 4 (right), on the other hand, the transition from racemic product steady states to higher purity steady states is smooth. The higher the residence time provided for the racemic feed mixture to undergo Viedma ripening, the higher the final product purity. However, this increase in enantiomeric excess at higher residence times is clearly flattening off, indicating that there are diminishing returns. This means that when striving for high enantiomeric purity, the productivity will decrease, as already shown in the results of the shortcut method (cf. Figure 3). In this case, the productivity is proportional to the feed rate and only values much lower than for flowsheet (A) are reached in the parameter region studied. The suspension density data indicates that very dilute suspensions are present in 
the crystallizer.

For both flowsheets, the low suspension densities obtained in the investigated parameter range indicate that there might be potential to improve the productivity by increasing the solid feed rate (flowsheet $(\mathrm{B})$ ) or the feed concentration (flowsheet $(\mathrm{A})$ ). In principle, the solid feed rate into the ripening stages of flowsheet (B) can be increased until the suspension becomes hard to stir. The feed concentration in flowsheet (A) on the other hand is typically limited by the thermal stability of the solute (since the feed is a clear solution, higher concentrations typically mean a higher feed temperature as well). We consider $70 \mathrm{~g}^{-1} \mathrm{~g}^{-1}$ realistic upper value for the feed concentration, as discussed in our previous work ${ }^{36}$. The Pareto set reported for flowsheet (A) in Figure 5 is therefore considered to be final and the pertinent question becomes whether there are any isothermal VR process configurations that allow overcoming the performance of flowsheet $(\mathrm{A})$.

To this end, we investigate the productivity/enantiomeric excess tradeoff of the single stage VR process when running it at a maximum allowable suspension density in Figure 6. We report results obtained using the shortcut method at suspension densities of $200 \mathrm{~kg} \mathrm{~m}^{-3}$ (left, blue lines) and $400 \mathrm{~kg} \mathrm{~m}^{-3}$ (right, green lines). These results were calculated from batch Viedma ripening curves as depicted in Figure 2 and scaled to describe the MSMPRC case as shown in Figure 3.

From a CRE perspective the minimum in the Levenspiel plot (cf. Figure 2 (middle)) gives the operating point where a chemical reaction features the highest conversion rate. For a VR process of flowsheet type (B), where all mechanisms involved in Viedma ripening occur, this can be understood as the point where the most distomer solids convert into the wanted stereoisomer per time. This operation point is found to be at an e.e. of 0.84 for the low and 0.86 for the high suspension density results. In Figure 6 the maximum de.e./ $\mathrm{d} t$ points are marked with red circles. Enantiomeric excesses higher than at this point can be achieved, but only when sacrificing productivity (solid lines to the left of the red points). Interestingly, we discovered that when aiming at a purity lower than the e.e. where 

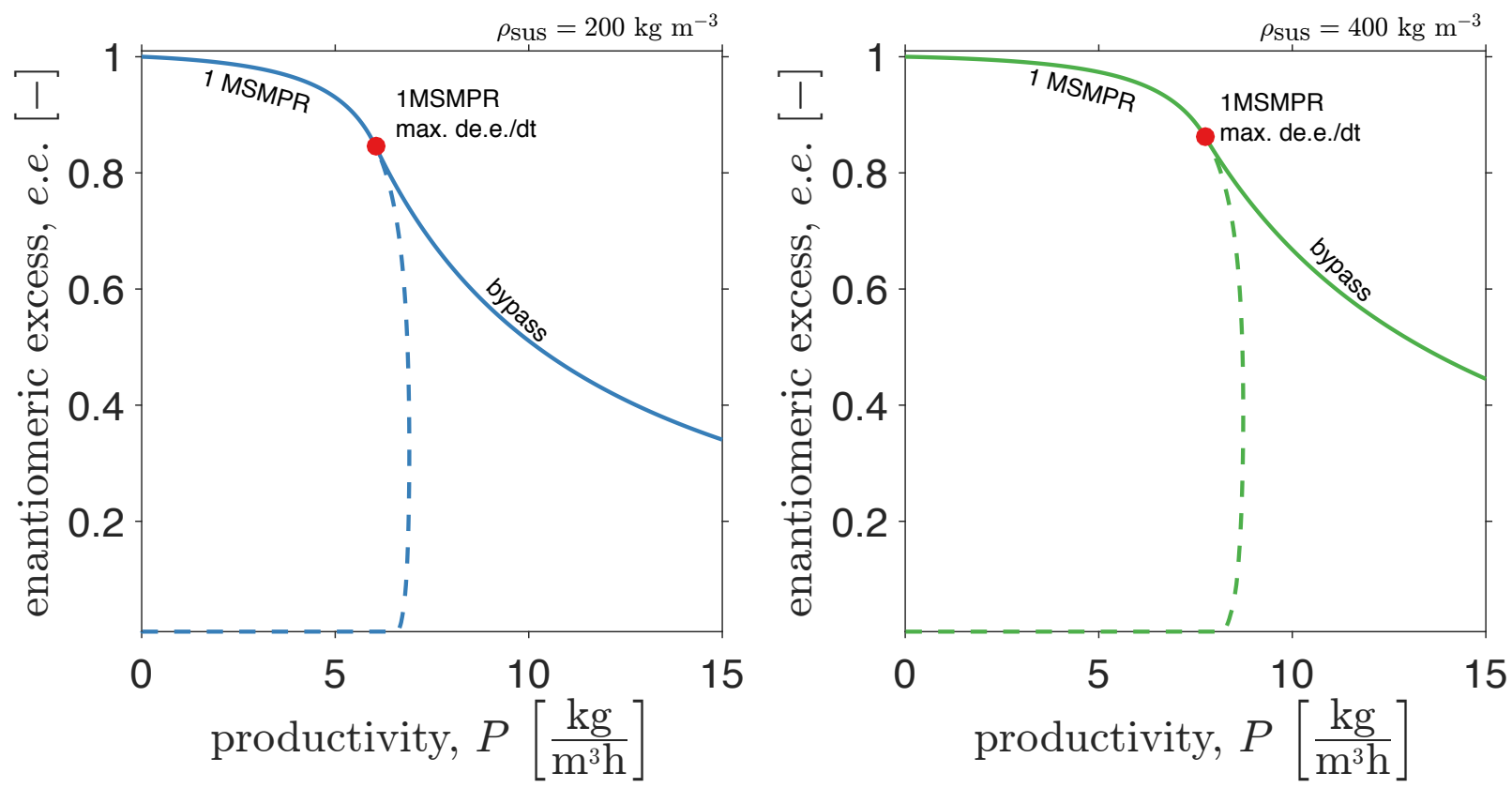

Figure 6: Productivity vs. enantiomeric purity data for one ripening stage in flowsheet (B) (cf. Figure 1) for suspension densities of $200 \mathrm{~kg} \mathrm{~m}^{-3}$ (left, blue lines) and $400 \mathrm{~kg} \mathrm{~m}^{-3}$ (right, green lines), respectively. The solid line represents Pareto optimal points including the use of the bypass. The dashed lines represent suboptimal points when the bypass would not be used. The filled red circle shows the point with maximum de.e./dt, i.e. the minimum in Figure 2 (middle).

the maximum de.e./ $\mathrm{d} t$ is found, it is beneficial to operate the MSMPRC at the maximum de.e./dt point, but to divert part of the (racemic) feed material through a bypass. This bypassing with subsequent blending of the solid product from the MSMPRC leads to a reduced enantiomeric purity, but higher productivity (drawn as the solid lines to the right of the red points). Such an operation is in fact advantageous from a productivity standpoint in comparison to operating the MSMPRC directly at lower enantiomeric excess (drawn as the dashed lines). Therefore, the complete solid lines drawn in Figure 6 represent the Pareto sets at the respective suspension density for a single ripening stage in flowsheet (B). All points below these curves are suboptimal. 


\subsection{Process configurations with multiple ripening stages}

As shown in Figure 6, the productivity of a ripening stage decreases drastically when aiming for high enantiomeric purity. In order to potentially improve this situation, we now consider processes with multiple ripening stages, as drawn in Figure 1 (B). Cascades of equal-sized crystallizers and cascades where the crystallizer sizes are varied freely will be considered in the following. In order to calculate the productivity of these processes the shortcut method based on the Levenspiel plot will be used again. With reference to Figures 2 and 6 it is clear that a single ripening stage process operated at the maximum de.e./dt point (and using the bypass to reach lower enantiomeric excesses) represents the most efficient process alternative for enantiomeric excesses equal or lower than at this point. For cascades of $n$ MSMPRCs the optimal process configurations can be conveniently found using the shortcut method by solving the following optimization problem:

$$
\begin{aligned}
& \underset{e . e_{. i}}{\operatorname{minimize}} \sum_{i=1}^{n} \frac{e . e_{\cdot i}-e . e_{\cdot i-1}}{\tilde{f}\left(e . e_{\cdot i}\right)} \\
& \text { subject to } e . e_{\cdot i} \geq e \cdot e_{\cdot i-1} \\
& e . e \cdot 0=e . e \cdot{ }_{\text {in }}=0 \\
& e . e_{\cdot n}=e . e_{\cdot \text { out }}
\end{aligned}
$$

where e.e. $i$ is the solid phase enantiomeric excess at steady state of the $i$-th MSMPRC and $\tilde{f}\left(e_{. e}\right)$ is the slope of the fingerprint curve (Eq. (9)) at the steady state enantiomeric excess found in the $i$-th crystallizer and e.e.out is the desired e.e. at the end of the cascade. In other words, we select the steady state enantiomeric excesses for all crystallizers so that the sum of the areas of the rectangles in the Levenspiel plot is minimized. The residence times for each crystallizer can then be found using

$$
\tau_{i}=\frac{e . e_{\cdot i}-e \cdot e_{\cdot i-1}}{\tilde{f}\left(e . e_{\cdot i}\right)}
$$



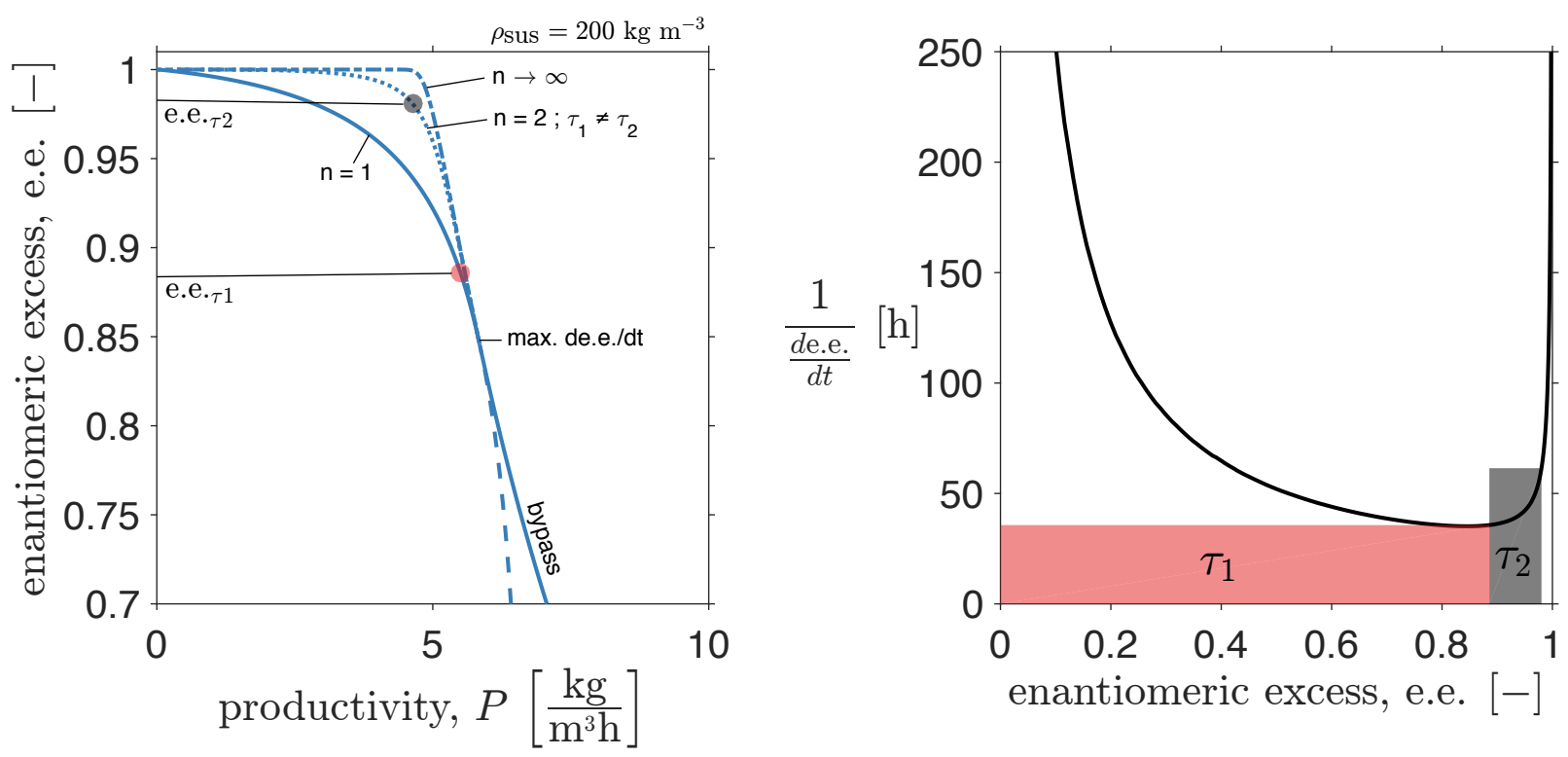

Figure 7: (left) Productivity vs. enantiomeric excess data for process configurations with different numbers of ripening stages with variable sizes operated at $\rho_{\text {sus }}=200 \mathrm{~kg} \mathrm{~m}^{-3}$. Solid line: one ripening stage $(n=1)$; dotted line: two ripening stages $(n=2)$; dash-dotted line: $n \rightarrow \infty$. (right) Levenspiel plot of the optimal cascade reaching an enantiomeric excess of 0.98. The residence times of the first and second MSMPRC are drawn as the red and grey rectangles, respectively. The operating point of the first crystallizer is drawn in red in the left plot, while the operating point of the overall cascade is drawn in grey.

and the overall productivity of the process cascade can be calculated with Eqs. (2) and (11). We have drawn all such process configurations for two MSMPRCs in Figure 7 (left) as the dotted line.

The Levenspiel plot for a two MSMPRC cascade reaching e.e. out $=0.98$ is drawn in Figure 7 (right) where the residence times of the crystallizers are shown with the rectangles. That this configuration is more efficient (higher productivity) than a single ripening stage reaching the same enantiomeric excess can be seen from the fact that a single rectangle reaching the same enantiomeric excess has a larger area (higher residence time) than the two MSMPRC cascade drawn in this figure. Note also that the operating point of the first MSMPRC is towards higher e.e. than at the maximum de.e./ $\mathrm{d} t$ point; in fact, the operating point of the first MSMPRC shifts further away from this point the higher the desired e.e. out. For a cascade with variably sized MSMPRCs adding more vessels will always be beneficial 
in increasing productivity at the same e.e.out. In the limiting case of an infinite number of crystallizers $(n \rightarrow \infty)$ after the maximum de.e./ $\mathrm{d} t$ point, one would obtain the integral under the curve for the residence time required after the first MSMPRC. However, there will again be diminishing returns for every further crystallizer added. We have drawn this limiting case in Figure 7 using the dash-dotted line.

The second design approach is to use equal sized crystallizers in the MSMPRC cascade. Using the shortcut method, we have drawn these process configurations in the productivity vs. enantiomeric excess plot as a dashed line in Figure 8 (left, $n=2 ; \tau_{1}=\tau_{2}$ ). Running the crystallizers with equal residence times means that the first crystallizer is often forced to operate at enantiomeric excesses far below the maximum de.e./ $\mathrm{d} t$ point. This results in suboptimal configurations in a Pareto sense; in fact many are worse than a single MSMPRC with the same overall residence time. Interestingly, the curve for cascades with two equalsized MSMPRCs (dashed line) crosses the Pareto set obtained for a single MSMPRC (solid line), drawn into Figure 8 (right), where the grey area gives the residence time of the first $\operatorname{MSMPRC}\left(\tau_{1}\right)$ and the yellow area gives the residence time of the second MSMPRC $\left(\tau_{2}\right)$. Clearly, a single MSMPRC with $\tau=\tau_{1}+\tau_{2}=2 \tau_{1}=2 \tau_{2}$ gives the same performance; hence the intersection. Moving towards higher enantiomeric excesses, we find that the equal-sized 2 MSMPRC cascade approaches the performance of the 2 MSMPRC cascade with variable residence times in the two crystallizers; however, it always stays (slightly) below this more general case. The blue circles drawn in Figure 8 (left) are steady state results obtained from the full PBE model that was run with two MSMPRCs with equal residence times. They show excellent overlap with the results obtained from the shortcut method, which further validates it.

It is noteworthy that the Pareto set of a cascade with three equal-sized MSMPRCs cannot have an intersection with the Pareto set for one MSMPRC as long as the fingerprint curve (solid line in Figure 2 (left) and (middle)) does not change its shape drastically (no such cases are known in the literature). This would indicate that the performance of an MSMPRC 

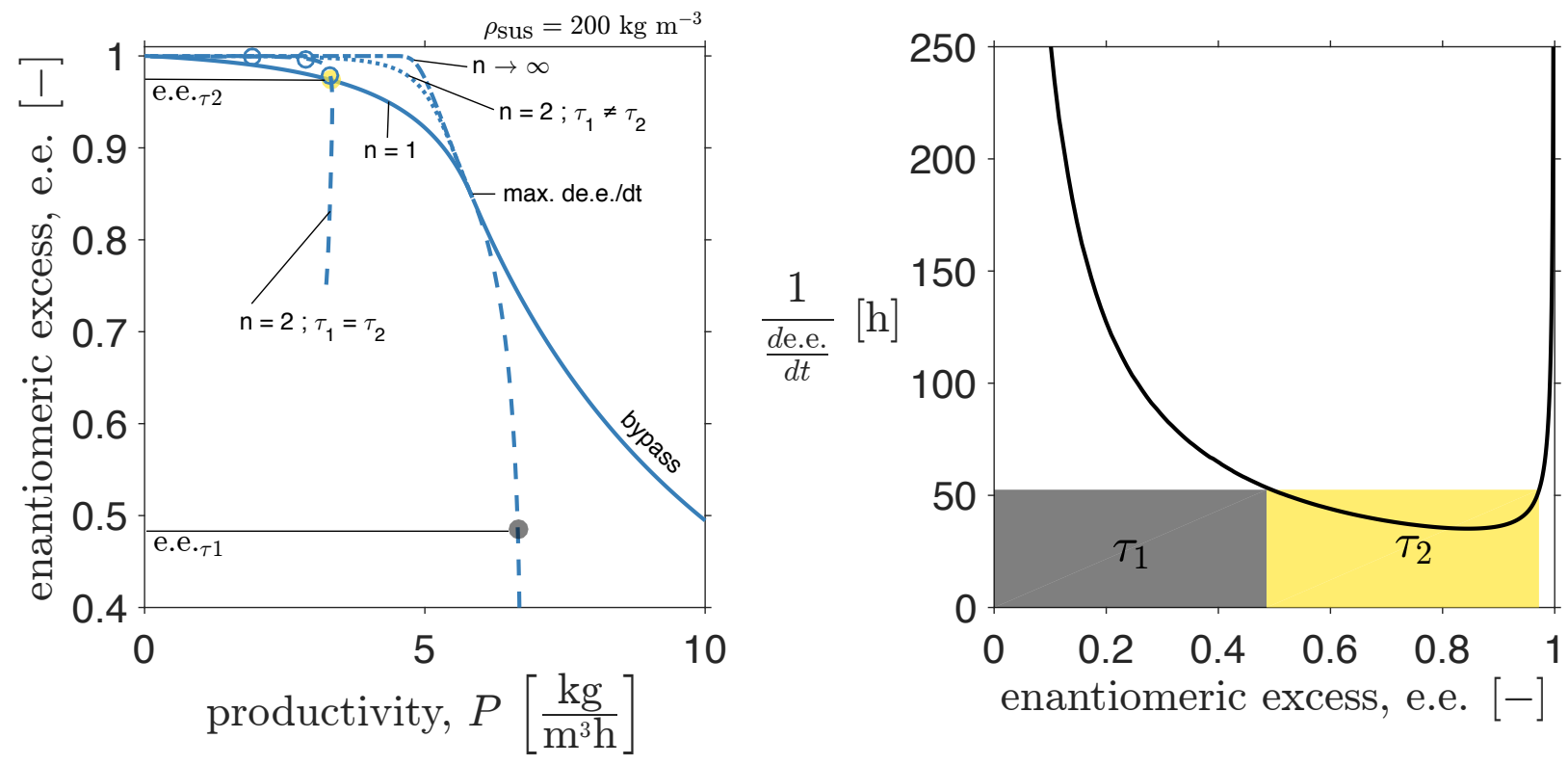

Figure 8: (left) Productivity vs. enantiomeric excess data for cascades with two equal-sized ripening stages operated at $\rho_{\text {sus }}=200 \mathrm{~kg} \mathrm{~m}^{-3}$ drawn as a dashed line (obtained using the shortcut method). The blue circles represent simulation results using the full PBE model, which are in excellent agreement with the shortcut method. For comparison purposes, we have also drawn the $n=1$ (solid line) and variable size cascades for $n=2$ (dotted line) and $n \rightarrow \infty$ (dash-dotted line). (right) Levenspiel plot of the cascade with equal performance to a single MSMPRC (point where the Pareto set for one MSMPRC (solid line) and two MSMPRC cascade with equal volume (dashed line) intersect). The operating point of the first crystallizer is drawn in grey in the left plot, while the operating point of the overall cascade is drawn in yellow. 
cascade with $n$ crystallizers with equal residence times $\left(n \geq 3 ; \tau_{1}=\tau_{2}=\cdots=\tau_{n}\right)$ is always worse than the performance of a single MSMPRC of residence time $n \tau_{1}$. We now possess a complete picture of the performance of the different process variants presented in Figure 1 and are drawing conclusions in the final section of this work.

\section{Concluding remarks}

In this work Pareto-optimal operating strategies for both, the PC and VR process, were presented, where we have focused on two key performance indicators, enantiomeric purity of the produced solids and the productivity of the process configurations. In generating these results, we highlight that the same kinetics and the same phase diagram have been used for both process types, which is the only way an unbiased comparison can be made. For the flowsheet presented in Figure 1 (B) we have considered the performance of a single ripening stage, as well as cascades of two (and more) ripening stages (either with equal residence time or with varying residence time). We have shown that the two MSMPRC cascade with equal residence times performs worse than the two MSMPRC cascade with variable residence times unless a very high enantiomeric purity is demanded (where the two cases perform roughly equivalently). Adding further crystallizers does not boost the productivity substantially for the variable residence time case; in the case of equal-sized MSMPRCs, the addition would even be detrimental. Since the shape of the fingerprint curve in the Levenspiel plot is similar for all VR experiments presented in the literature that are known to us, it suggests that these findings are valid regardless of substance system.

The Pareto sets for the PC process and the VR process with variable residence times are summarized in Figure 9 where we also show the Pareto sets obtained for the ripening stages at even higher suspension density (400 $\mathrm{kg} \mathrm{m}^{-3}$, green lines). The comparison between the 200 $\mathrm{kg} \mathrm{m}^{-3}$ (blue lines) and $400 \mathrm{~kg} \mathrm{~m}^{-3}$ cases shows that the productivity does not scale linearly with the suspension density, but that there are clearly diminishing returns. Furthermore, it 


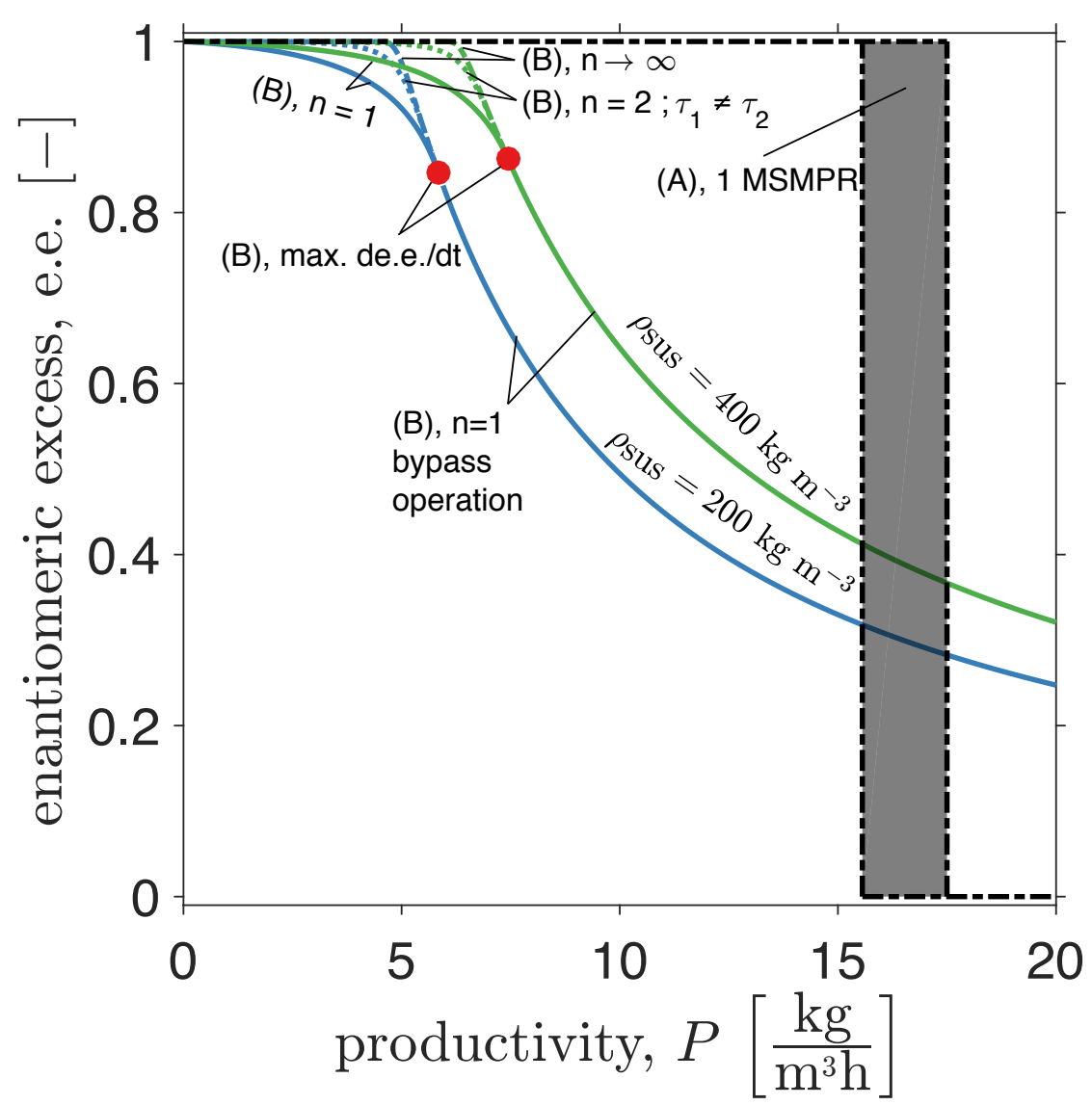

Figure 9: Comparison of Pareto-optimal operating strategies with respect to solid phase enantiomeric excess and productivity for the PC process (black dashed lines, cf. Figure 1 (A) for its flowsheet) and the ripening stages in Figure 1 (B) operated at suspension densities of $200 \mathrm{~kg} \mathrm{~m}^{-3}$ (blue lines) and $400 \mathrm{~kg} \mathrm{~m}^{-3}$ (green lines), respectively. The Pareto set for one ripening stage is shown as the solid lines, while dotted and dash-dotted line represent MSMPRC cascades with $n=2$ and $n \rightarrow \infty$ with variable residence times, respectively. Passing the red dots, the one MSMPRC case with bypass always outperforms the cascades.

should be noted that the Pareto sets presented for the ripening stages do not take the precrystallization stage into account, i.e., these Pareto sets must be understood as optimistic, because the pre-crystallization stage itself has a finite productivity. Even with this optimistic interpretation of the data, we conclude that the PC process outperforms the processes that rely on ripening stages in terms of productivity; at least for the specific set of kinetics chosen in this work. That said, the PC process operates away from the thermodynamic equilibrium and the process conditions must be tuned in a way that no substantial nucleation of the distomer occurs in the crystallizer. Unfortunately, the highest productivity points (close to 
the step in Figure 9) are where this balance is most delicate. Therefore, the operation of the process with ripening stages might still be worthwhile in cases where process robustness is the major concern. In such cases, a tradeoff between process robustness and productivity should be sought (we have not tried to quantify such a tradeoff in the present work).

In developing the results mentioned above, the computational burden of the full population balance equation model has motivated us to design a shortcut method that is computationally fast, but still yields adequate results. We have shown that such a model can be established from a single simulation run of a batch Viedma ripening process using the full process model and well known chemical reaction engineering principles. We have shown that the results of the shortcut method emulate the results obtained from the full process model very well, at least for the set of kinetics parameters considered here. The limits of validity of this shortcut method will be the subject of future work. Apart from the reducing the computational burden of the full process model, the shortcut method-if it turns out to be generally applicable-has wider implications. Measuring the phase diagram data, as well as estimating all kinetic parameters (for growth, agglomeration, breakage, etc.) in the full process model with reasonable precision requires a significant amount of experimental data. In contrast to that, the shortcut method requires only minimal data. It is therefore conceivable to use an enantiomeric excess vs. time trajectory obtained from an isothermal batch Viedma ripening experiment to arrive at Pareto-optimal processes in terms of productivity and enantiomeric excess. If more in depth data is required (e.g., about the particle size distribution), the full process model would, however, still be required.

\section{Acknowledgement}

TK thanks The University of Manchester for providing a PhD scholarship. 


\section{Supporting Information Available}

Details about productivity calculations in the literature review (see Table 1) and a nomenclature table are provided.

\section{References}

(1) De Camp, W. H. The FDA perspective on the development of stereoisomers. Chirality 1989, $1,2-6$.

(2) Calcaterra, A.; D'acquarica, I. The market of chiral drugs: Chiral switches versus de novo enantiomerically pure compounds. J. Pharm. Biomed. Anal. 2017,

(3) Nunez, M. C.; Garcia-Rubino, M. E.; Conejo-Garcia, A.; Cruz-Lopez, O.; Kimatrai, M.; Gallo, M. A.; Espinosa, A.; Campos, J. M. Homochiral drugs: a demanding tendency of the pharmaceutical industry. Curr. Med. Chem 2009, 16, 2064-2074.

(4) Lorenz, H.; Seidel-Morgenstern, A. Processes to separate enantiomers. Angew. Chem. Int. Ed. Engl. 2014, 53, 1218-1250.

(5) Rajendran, A.; Paredes, G.; Mazzotti, M. Simulated moving bed chromatography for the separation of enantiomers. J. Chromatogr. A 2009, 1216, 709-738.

(6) Lorenz, H.; Sheehan, P.; Seidel-Morgenstern, A. Coupling of simulated moving bed chromatography and fractional crystallisation for efficient enantioseparation. J. Chromatogr. A 2001, 908, 201-214.

(7) Xie, R.; Chu, L.-Y.; Deng, J.-G. Membranes and membrane processes for chiral resolution. Chem. Soc. Rev. 2008, 37, 1243-1263.

(8) Gilks, S. E.; Davey, R. J. Crystallisation from a Water-in-Oil Emulsion as a Route to Enantiomer Separation: The Case of DL-Threonine. Chem. Eur. J. 2016, 22, 74-78.

(9) Jacques, J.; Collet, A.; Wilen, S. H. Enantiomers, racemates, and resolutions; Wiley, 1981.

(10) Schroer, J.; Wibowo, C.; Ng, K. Synthesis of chiral crystallization processes. AIChE J. 2001, 47, 369-387.

(11) Sakai, K.; Hirayama, N.; Tamura, R. Novel Optical Resolution Techniques; Springer, 2007.

(12) Viedma, C. Chiral symmetry breaking during crystallization: complete chiral purity induced by nonlinear autocatalysis and recycling. Phys. Rev. Lett. 2005, 94, 065504. 
(13) Noorduin, W. L.; Izumi, T.; Millemaggi, A.; Leeman, M.; Meekes, H.; Van Enckevort, W. J. P.; Kellogg, R. M.; Kaptein, B.; Vlieg, E.; Blackmond, D. G. Emergence of a single solid chiral state from a nearly racemic amino acid derivative. J. Am. Chem. Soc. 2008, 130, 1158-1159.

(14) Iggland, M.; Mazzotti, M. A population balance model for chiral resolution via Viedma ripening. Cryst. Growth Des. 2011, 11, 4611-4622.

(15) Lorenz, H.; Polenske, D.; Seidel-Morgenstern, A. Application of preferential crystallization to resolve racemic compounds in a hybrid process. Chirality 2006, 18, 828-840.

(16) Elsner, M. P.; Ziomek, G.; Seidel-Morgenstern, A. Simultaneous preferential crystallization in a coupled, batch operation mode-Part I: Theoretical analysis and optimization. Chem. Eng. Sci. 2007, 62, 4760-4769.

(17) Elsner, M. P.; Ziomek, G.; Seidel-Morgenstern, A. Efficient separation of enantiomers by preferential crystallization in two coupled vessels. AIChE Journal 2009, 55, 640-649.

(18) Qamar, S.; Elsner, M. P.; Hussain, I.; Seidel-Morgenstern, A. Seeding strategies and residence time characteristics of continuous preferential crystallization. Chem. Eng. Sci. 2012, $71,5-17$.

(19) Qamar, S.; Galan, K.; Elsner, M. P.; Hussain, I.; Seidel-Morgenstern, A. Theoretical investigation of simultaneous continuous preferential crystallization in a coupled mode. Chem. Eng. Sci. 2013, 98, 25-39.

(20) Chaaban, J. H.; Dam-Johansen, K.; Skovby, T.; Kiil, S. Separation of enantiomers by continuous preferential crystallization: Experimental realization using a coupled crystallizer configuration. Org. Process Res. Dev. 2013, 17, 1010-1020.

(21) Galan, K.; Eicke, M. J.; Elsner, M. P.; Lorenz, H.; Seidel-Morgenstern, A. Continuous Preferential Crystallization of chiral molecules in single and coupled Mixed-Suspension Mixed-Product-Removal crystallizers. Cryst. Growth Des. 2015, 15, 1808-1818.

(22) Rougeot, C.; Hein, J. E. Application of Continuous Preferential Crystallization to Efficiently Access Enantiopure Chemicals. Org. Process Res. Dev. 2015,

(23) Vetter, T.; Burcham, C. L.; Doherty, M. F. Separation of conglomerate forming enantiomers using a novel continuous preferential crystallization process. AIChE Journal 2015, 61, 2810-2823.

(24) Binev, D.; Seidel-Morgenstern, A.; Lorenz, H. Continuous separation of isomers in fluidized bed crystallizers. Cryst. Growth Des. 2016, 16, 1409-1419.

(25) Noorduin, W. L.; Meekes, H.; van Enckevort, W. J. P.; Millemaggi, A.; Leeman, M.; Kaptein, B.; Kellogg, R. M.; Vlieg, E. Complete Deracemization by Attrition-Enhanced Ostwald Ripening Elucidated. Angew. Chem. Int. Ed. Engl. 2008, 47, 6445-6447. 
(26) Engwerda, A.; Koning, N.; Tinnemans, P.; Meekes, H.; Bickelhaupt, F.; Rutjes, F.; Vlieg, E. Deracemization of a Racemic Allylic Sulfoxide Using Viedma Ripening. Crsty. Growth Des. 2017, 17, 4454-4457.

(27) Spix, L.; Meekes, H.; Blaauw, R.; Enckevort, W.; Vlieg, E. Complete Deracemization of Proteinogenic Glutamic Acid Using Viedma Ripening on a Metastable Conglomerate. Crsty. Growth Des. 2012, 12, 5796-5799.

(28) Viedma, C.; Ortiz, J. E.; Torres, T. d.; Izumi, T.; Blackmond, D. G. Evolution of solid phase homochirality for a proteinogenic amino acid. J. Am. Chem. Soc 2008, 130, $15274-15275$.

(29) Noorduin, W. L.; Kaptein, B.; Meekes, H.; van Enckevort, W. J. P.; Kellogg, R. M.; Vlieg, E. Fast attrition-enhanced deracemization of naproxen by a gradual in situ feed. Angew. Chem. Int. Ed. Engl. 2009, 48, 4581-4583.

(30) Xiouras, C.; Van Aeken, J.; Panis, J.; Ter Horst, J. H.; Van Gerven, T.; Stefanidis, G. D. Attrition-enhanced deracemization of $\mathrm{NaClO} 3$ : Comparison between ultrasonic and abrasive grinding. Cryst. Growth Des. 2015, 15, 5476-5484.

(31) Rougeot, C.; Guillen, F.; Plaquevent, J.-C.; Coquerel, G. Ultrasound-Enhanced Deracemization: Toward the Existence of Agonist Effects in the Interpretation of Spontaneous Symmetry Breaking. Cryst. Growth Des. 2015,

(32) Suwannasang, K.; Flood, A. E.; Rougeot, C.; Coquerel, G. Using programmed heatingcooling cycles with racemization in solution for complete symmetry breaking of a conglomerate forming system. Cryst. Growth Des. 2013, 13, 3498-3504.

(33) Suwannasang, K.; Flood, A. E.; Coquerel, G. A Novel Design Approach To Scale Up the Temperature Cycle Enhanced Deracemization Process: Coupled Mixed-Suspension Vessels. Cryst. Growth Des. 2016, 16, 6461-6467.

(34) Kaemmerer, H.; Horvath, Z.; Lee, J.; Kaspereit, M.; Arnell, R.; Hedberg, M.; Herschend, B.; Jones, M.; Larson, K.; Lorenz, H.; Seidel-Morgenstern, A. Separation of Racemic Bicalutamide by an Optimized Combination of Continuous Chromatography and Selective Crystallization. Org. Process Res. Devel. 2012, 16, 331-342.

(35) Vetter, T.; Burcham, C. L.; Doherty, M. F. Regions of attainable particle sizes in continuous and batch crystallization processes. Chem. Eng. Sci. 2014, 106, 167-180.

(36) Köllges, T.; Vetter, T. Model-based analysis of continuous crystallization/reaction processes separating conglomerate forming enantiomers. Cryst. Growth Des. 2017, 17, $233-247$.

(37) Li, W.; Spix, L.; S.C.A., d.; Meekes, H.; Kramer, H.; Vlieg, E.; ter Horst, J. Deracemization of a Racemic Compound via Its Conglomerate-Forming Salt Using Temperature Cycling. Crsty. Growth Des. 2016, 16, 5563-5570. 
(38) Hein, J. E.; Cao, B. H.; van der Meijden, M. W.; Leeman, M.; Kellogg, R. M. Resolution of Omeprazole Using Coupled Preferential Crystallization: Efficient Separation of a Nonracemizable Conglomerate Salt under Near-Equilibrium Conditions. Org. Process Res. Dev. 2013, 17, 946-950.

(39) Elsner, M. P.; Ziomek, G.; Seidel-Morgenstern, A. Simultaneous preferential crystallization in a coupled batch operation mode. Part II: Experimental study and model refinement. Chem. Eng. Sci. 2011, 66, 1269-1284.

(40) Drioli, E.; Di Profio, G.; Curcio, E. Membrane-assisted crystallization technology; World Scientific, 2015.

(41) Levenspiel, O. Chemical reaction engineering; Wiley, 1998. 


\section{For Table of Contents Use Only}

Title: Design and Performance Assessment of Continuous Crystallization Processes Resolving Racemic Conglomerates

Authors: Till Köllges, Thomas Vetter

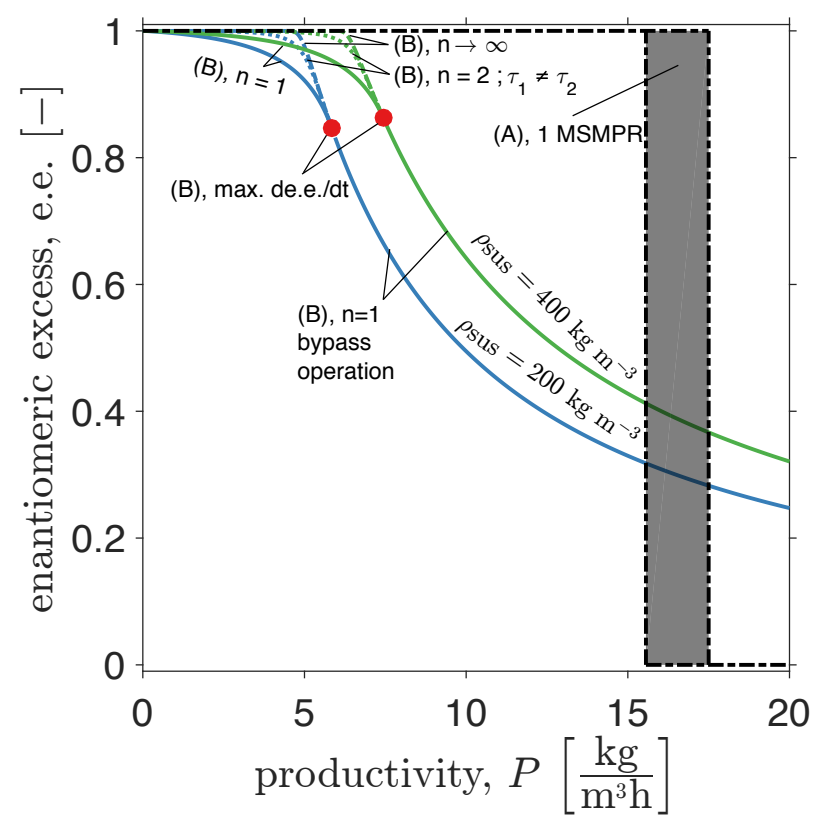

Synopsis: Several continuous processing variants that enable the separation of enantiomers forming conglomerates in the solid state are presented. The process configurations are quantitatively assessed based on the attainable enantiomeric excess and productivity and Paretooptimal solutions are reported. It is shown that such Pareto-optimal solutions can be rapidly obtained using a shortcut method rather than a mechanistic population balance equation model. 